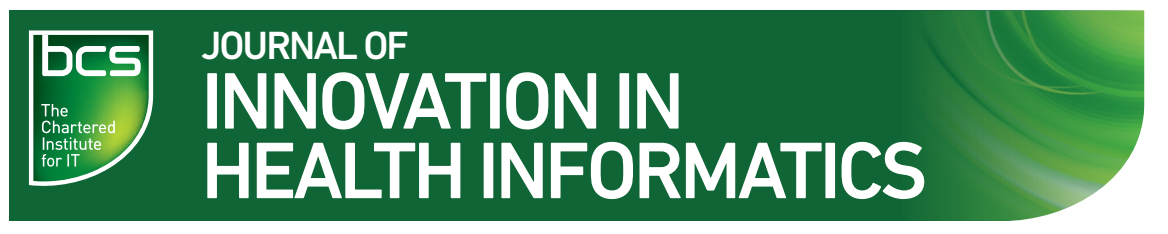

\title{
Journal of Innovation in Health \\ Informatics: building on the 20-year history of a BCS Health peer review journal
}

\section{Simon de Lusignan}

University of Surrey, Guildford, UK

Editor-in-Chief Journal of Innovation in Health Informatics

\section{ABSTRACT}

After 20-years as Informatics in Primary Care the journal is renamed Journal of Innovation in Health Informatics. The title was carefully selected to reflect that:

(1) informatics provides the opportunity to innovate rather than simply automates;

(2) implementing informatics solutions often results in unintended consequences, and many implementations fail and benefits and innovations may go unrecognised;

(3) health informatics is a boundary spanning discipline and is by its very nature likely to give rise to innovation.

Copyright $\odot 2015$ The Author(s). Published by BCS, The Chartered Institute for IT under Creative Commons license http://creativecommons.org/ licenses/by/4.0/ 


\section{Informatics as a science}

Informatics can be characterised as either a science, be defined as a profession or have technology based definitions. ${ }^{2}$ We have long advocated that informatics is defined as a scientific discipline ${ }^{3,4}$ as this focusses the need for the development of theory and hypotheses. The latter should be tested through well-designed research to develop an evidence-base.

Informatics is the scientific study of the use and processing of data, information and knowledge. ${ }^{5}$

\section{Informatics is not just automating data flow; it provides scope to innovate}

Informatics is not just the transferring of tasks previously done on paper into computerised processes. It is recognising that, when this happens, there is scope for innovation based on the different ways the generated information can be used and the genesis of new products based on this information. This was a key observation of Zuboff in her landmark work The Age of the Smart Machine. ${ }^{6}$

The Clinical Practice Research Database (CPRD) and the Royal College of General Practitioners (RCGP) Research and Surveillance Centre (RSC) are examples of how routinely recorded health data are used for research and surveillance respectively. ${ }^{7}$ The latter is the biggest supplier of data to the UK assessment of flu vaccine effectiveness this year; this assessment suggests its effectiveness has been suboptimal. $^{8}$

\section{REFERENCES}

1. BCS Health. http://www.bcs.org/category/9373.

2. Staggers N, Thompson CR. The evolution of definitions for nursing informatics: a critical analysis and revised definition. J Am Med Inform Assoc. 2002;9:255-61.

3. de Lusignan $\mathrm{S}$. What is primary care informatics? J Am Med Inform Assoc. 2003 Jul-Aug;10(4):304-9.

4. Pigott K, de Lusignan S, Rapley A, Robinson J, PritchardCopley A. An informatics benchmarking statement. Methods Inf Med. 2007;46(4):394-8.

5. van Bemmel JH, Musen MA. Handbook of Medical Informatics. Heidelberg: Springer-Verlag, 1997.

6. Zuboff S. In the Age of the Smart Machine: The Future of Work and Power. New York; Basic Books, 1988.

7. Kousoulis AA, Rafi I, de Lusignan S. The CPRD and the RCGP: building on research success by enhancing benefits for patients and practices. Br J Gen Pract. 2015 Feb;65(631):54-5. doi: 10.3399/bjgp15X683353.

8. Pebody RG, Warburton F, Ellis J, Andrews N, Thompson C, von Wissmann B, Green HK, Cottrell S, Johnston J, de Lusignan S, Moore C, Gunson R, Robertson C, McMenamin J,

\section{Informatics projects often end up with unintended consequences}

Many informatics projects do not realise the benefits anticipated, and often have other unintended consequences. This has been a long recognised issue in health informatics. ${ }^{9}$ Implementations are often challenging, as we have seen within the NHS. ${ }^{10}$ There is an urgent need to learn how to innovate effectively, and learn the lessons from previous implementations. ${ }^{11}$

\section{Informatics and innovation as boundary- spanning phenomena}

Finally, both informatics and innovation happen best when they span traditional discipline boundaries. Boundaryspanners are the people in an innovative system who have or adopt the role of linking an organisation's internal networks with external sources of information. ${ }^{12}$ Much of the work in informatics is boundary-spanning. Many consider that health informatics spans:

- medical, health and social care;

- management science; and

- computing and information technology.

An effective informatics professional is one who can be involved in knowledge brokering between disciplines and across complex organisations.

The Journal of Innovation in Health Informatics is launched with this issue. The new name provides focus on what informatics is about, and what informaticians should aspire to be.

Zambon M. Low effectiveness of seasonal influenza vaccine in preventing laboratory-confirmed influenza in primary care in the United Kingdom: 2014/15 mid-season results. Euro Surveill. 2015;20(5):pii=21025. http://www.eurosurveillance.org/ ViewArticle.aspx?Articleld=21025.

9. Ash JS, Berg M, Coiera E. Some unintended consequences of information technology in health care: the nature of patient care information system-related errors. J Am Med Inform Assoc. 2004 Mar-Apr;11(2):104-12.

10. Greenhalgh T, Stramer K, Bratan T, Byrne E, Russell J, Potts HW. Adoption and non-adoption of a shared electronic summary record in England: a mixed-method case study. BMJ. 2010 Jun 16;340:c3111. doi: 10.1136/bmj.c3111.

11. de Lusignan S, Krause P. The Hayes principles: learning from the national pilot of information technology and core generalisable theory in informatics. Inform Prim Care. 2010;18(2):73-7.

12. Tushman M. Special Boundary Roles in the Innovation Process. Administrative Science Quarterly 1977;22 (4):587-605. doi:10.2307/2392402. ISSN 0001-8392. 